Submission \#10875

\title{
RESPONDING TO IDENTITY AND REPUTATION DISSONANCE IN A MANAGEMENT CONSULTING FIRM
}

\author{
WILLIAM S. HARVEY \\ University of Exeter \\ TIMOTHY MORRIS \\ University of Oxford \\ MILENA MUELLER SANTOS \\ University of Oxford
}

INTRODUCTION

Research on reputation building suggests that it is linked to an organization's identity. For example, Fombrun (2012) argues that companies with strong identities are more likely to gain attention and appreciation. While it is accepted that identity and reputation differ, we know little about how organizations manage the tensions that this may create. How, therefore, do organizations respond when identity claims are inconsistent with reputation? To examine this question we focus on a large management consulting firm. We contribute to reputation theory by identifying three mechanisms focused on work winning and execution that, collectively, help employees to bridge the gap between claimed identity and reputation. We suggest that these mechanisms help sustain the organization's identity in the face of conflicting reputational evidence.

\section{THEORY}

Reputation is based on evaluations of outsiders relative to other organizations and is derived from experience from third party judgments. It is a social evaluation that is 'broadly defined as stakeholder perceptions with regard to an organization's ability to deliver valued outcomes' (Rindova et al., 2010: 610) and that make it distinctive from others in its peer group. As a distinctive attribute of an organization, a positive reputation is a valuable intangible asset potentially offering non-trivial forms of competitive advantage (Boyd et al., 2010). Foreman et al. (2012: 180) propose that reputation is derived from organizational identity because 'an organization generally acts in ways that are consistent with its "self-view" and thereby supports the nature of claims to distinctiveness. In other words, identity will help to inform an organization's members' views of their reputation and, through the values and behaviors they display as a result of the organization's identity, will affect how external parties form reputational judgments. Organizational identity refers to 'who we are' (Albert and Whetten, 1985) and 'how we see ourselves' (Chun, 2005). It reflects central and enduring characteristics that make the organization distinctive (CED) (Albert and Whetten, 1985) and suggests that members of organizations have a collective, shared understanding of its distinctive values and characteristics (Hatch and Schultz, 2002). It implies a degree of difference from other organizations to which the focal firm wishes to be compared but also enough similarity that the firm can be readily accepted as part of that set (Deephouse, 1999).

However, there are three theoretical problems with the notion that reputation is the external expression of an organization's identity. First, while identity influences reputation building, it does not fully determine it and reputation is not simply an external reflection of identity. Stakeholders will draw on a range of cues and selectively use information from 
multiple sources to judge reputation. Second, more recent scholarship has also questioned some of the core assumptions of the CED model of organizational identity in ways that have implications for the links to reputation proposed above. For one thing, it has been argued that identity may not always be enduring and may be more unstable than is implied by the CED properties (Gioia et al., 2013). The relatively unitarist notion of a single organizational identity to which all members adhere is contestable, not least because identity can intersect and influence at the institutional, organizational, individual and meta level (Albert and Whetten, 1985; Patvardhan et al., 2015). Third, there are many organizations where a unitary reputation does not exist. Indeed, theories of reputation suggest that organizations, or particular parts of them, will be perceived in different ways by different stakeholders and that the salience of particular qualities will vary between them (Lange et al., 2011). For example, employees are likely to be more concerned about the firm's reputation as an employer while customers will be concerned about its ability to deliver valued outputs in the form of goods or services (Barnett and Pollock 2012). In some organizations, notably professional services and other knowledge based firms, the reputation of a practice area or partner will be at least as important as the overall reputation of the firm (Greenwood et al. 2005; von Nordenflycht 2010).

Management consulting, like other professional service firms, represents an extreme case where many of the tensions between identity and reputation come together. The outputs of professional service firms are intangible and judging quality is made more difficult by the prolonged production process in which clients frequently engage in co-production with their professional advisors (Armbrüster, 2004; Clark, 1993; Mills et al., 1984; Morris and Empson, 1998). Consequently, reputation is important for professional service firms as a means of reducing client uncertainty about the quality of work (Coffee 2006; Greenwood et al., 2005; Sherer and Lee, 2002; Starbuck, 1992; Sturdy et al., 2013). Reputation is particularly important in management consulting because this sector has characteristics that make quality difficult to judge even relative to other professional services. These include a more ambiguous set of knowledge claims (Clark and Salaman, 1998) and an absence of formal professional qualifications that might act as a signal of quality control or barrier to entry (Faust, 2002). Building and projecting an appropriate identity is also important and strongly emphasized by consulting and other professional service firms as a means of normative control and as a means of signaling distinctiveness to parties with which they seek to interact (Alvesson and Empson 2008; Greenwood et al. 2010). Together these distinctive characteristics of management consulting and other professional service firms mean that the relationship between reputation and identity is more complex and dynamic than has been theorized.

In summary, we know that reputation is an important asset for firms and particularly for professional service firms, including management consultants. Identity plays an important role in reputation building because firms, and their employees, act in ways that are consistent with their self-view. But identity may also be inconsistent with reputation, and identity is likely to be a more fluid and pluralistic concept than is implied by the notion of a single organizational identity, particularly in the loose coalitions that constitute professional service firms. We therefore explore the implications of conflict and contradiction between a firm's identity claims and its reputation and how these can be managed. This leads us to ask the following research question:

How do organizations respond when identity claims are inconsistent with reputation? 


\section{METHODS}

We undertook exploratory research within a large global management consulting firm and its clients. We were interested in a research site for exploring the relationship between identity and reputation in the context of a broader research agenda around how organizations manage reputation. The organization (forthwith termed Augur Insights) has a single, broad line of consulting services that it groups around the description of strategy consulting. The firm is wholly owned by its partners, managed by a small executive team, and is consistently ranked by external validators such as Kennedy Consulting Research \& Advisory as a top ten global management consulting firm.

We adopted a multi-method approach of data collection, drawing upon interviews, focus groups, non-participant observation and archive materials to which we were given wide access. We undertook semi-structured interviews, lasting from 25-70 minutes. The interviews $(n=69)$ were conducted across a range of career levels but primarily we sought the views of senior members of the firm such as partners and directors as well as clients and non-clients. Our purpose was to build an understanding of the context in which consultants constructed reputation via interaction with clients and other parties as well as to obtain external views of the reputation of Augur Insights' practices. After the interviews had finished, discussions and reviews of findings also took place with partners. Two focus groups were conducted with key informants including senior employees and former employees who were now working for client firms to validate our findings. We also held three one-day meetings in 2011, 2012 and 2013 with a total of 24 partners from different practice areas in which a review of the findings and implications for the firm's reputation, both at the level of the firm and at the level of the practices and offices took place.

All recorded and non-recorded interviews were transcribed, uploaded and coded on the qualitative data analysis software, QSR NVivo9. A case profile was created for each interview, which contained demographic information about the interviewee. The first stage of data analysis involved data exploration during which we moved between the data and the existing literature on identity and reputation. We created a list of first order codes by initially reading through the fieldwork diary, transcripts and protocols, and identifying key themes from the interviews and our documentary data sources. In the second stage of data analysis we re-examined the data and our first order codes and synthesized into second order codes and three key categories for this paper (identity claims; reputation dissonance; remediation).

\section{Identity claims}

\section{FINDINGS}

When discussing how Augur Insights saw themselves and why they felt they were distinctive, interviewees referred to the idea that there was something unique about the firm as a whole and its component practices which underpinned its reputation building. Identity acted as a way of framing for the consultants why they were motivated and how the uniqueness of the firm contributed to the ability to produce high quality work. Our data show that there were three principal ways that the firm sought to project its identity claims. First, through building strong client relationships; second, through demonstrating entrepreneurialism; third, through providing practical solutions for their clients.

\section{Building strong client relationships}

Consultants took pride in building strong client relationships and they revealed that they felt individually responsible for ensuring a positive client experience that would encourage longlasting client relationships. 


\section{Entrepreneurialism}

Consultants used the term entrepreneurialism in their branding and work engagements to describe what made the firm distinctive internally and to clients. Entrepreneurialism implied openness to market opportunities and adaptability to client needs. It was used to contrast Augur Insights with other, large competitors that were better resourced but perceived to be less flexible in responding to client demands.

\section{Pragmatic solutions}

Consultants emphasized the firm's knowledge enabled them to deliver 'practical and implementable solutions', thereby distinguishing themselves from better-known competitors whom they described as abstract strategists, good at analysis but not so strong in execution. Thus: 'We pick up where [well known strategy consulting firm] drops off.' This meant that, in the view of Augur Insights' consultants, they customized solutions better than their competitors.

\section{Dissonance between identity and reputation.}

The problem for Augur Insights was that clients and others did not accept their claims uncritically. Augur Insights consultants themselves recognized some of their reputation limitations. We summarize the gap between claimed identity and reputation as a form of dissonance. Their identity claims around entrepreneurialism, for instance, were construed as permitting any sort of activity, whether it was consistent with its identity claims or not:

We talk about [being entrepreneurial] but that can just mean we do anything rather than have a distinctive expertise which we sell to clients (Partner).

It was often difficult to pinpoint for outsiders what this identity claim meant precisely. In general, there was an inconsistency between the identity claims of the firm and its reputation. Augur insights' own positioning as a strategy consultancy, albeit different from other strategy firms, was contested internally and externally. For many clients Augur Insights was a restructuring specialist and was closely involved in a number of high profile privatization programmes. In some instances, the firm's emphasis on both pragmatism and strategy actually contributed to a perceived lack of distinctiveness: "It's not a high level. I did not come out saying, wow I learned something today" (Client). Other clients also said pragmatism and strategy meant 'everything and nothing' and is 'too easy to assert' and 'every firm would say things like that'.

\section{Remediation}

The evidence above highlights that the firm's identity claims were not aligned with its reputation. This was not an organizational crisis, but was an important problem for the firm's credibility with clients to win the sort of work they wanted. When we asked Augur Insights consultants if and how they reconciled the gap between their claimed identity and the reputational perceptions of clients and others, they acknowledged what was seen as the 'strain' between the aspiration to be a strategy firm and the reality of their reputation among clients and outlined certain actions to address this. We identify three different remedial mechanisms that the firm adopted to address its reputational dissonance problem: first, changing levels; second, shifting identity and third, emphasizing value.

\section{Changing levels}

The first component involved the focus in the pitches and during projects centred on partner reputation rather than the reputation of Augur Insights itself. This suggests that there is not only an interaction between individual and organizational identity (Alvesson et al., 2008; Brown, 2014; Mangen and Brivot, 2014), but also between individual and organizational 
reputation. We found that partners were able to justify the firm's identity claims as they built trust with clients over time. Augur Insights' partners would reassure clients of their claims during the pitch by providing testimonials and by inviting previous clients (usually retired) to present with the pitch team. As both clients and consultants emphasized, this made sense because at the moment of sale, the client was concerned with the quality and integrity of the partner and his or her team, rather than the reputation of the firm as a whole.

\section{Shifting identity}

The second component entailed a different means of reinforcing the firm's identity. This entailed the partner acting as a 'disinterested' broker of useful knowledge about sector or market developments to clients with no explicit 'sell' involved: the partner therefore offered his/her expert information and insight to demonstrate competence or 'thought leadership'. This activity also countered the problems of pragmatism by suggesting partners did not simply 'chase the sale', but reinforced a particular firm identity. Partners built trust with clients through reassuring them with technical competence. For example, the firm attempted to increase its output of business knowledge through a variety of business publications which it makes freely available online and regularly distributes to its clients. This has followed the success of other major management consultancies which have built their legitimacy as business advisors through these outlets, and use of social media.

\section{Emphasizing value}

The third component relates back to the firm's pragmatic identity, which manifested in two ways. One was that the composition of teams was loaded more heavily with senior consultants including partners. This meant that the client received greater experience in the consulting project than might normally be offered by other competing firms and reinforced the firm's claimed identity of pragmatism. A second manifestation took the form of additional effort on client projects. As one Senior Manager put it: 'Going the extra mile for clients and making it tailor-made for clients.' This remedial action was more problematic because it is something that most consulting firms claim. Over-delivery was also seen as a business-winning tactic with few further ramifications.

\section{DISCUSSION}

In this paper we explore how identity and reputational differences may be managed. We argue that organizations and those that work within them have multiple identities, sometimes in conflict with each other and that some organizations have multiple reputations. Further, identity can clash with reputation when, for instance, it is built upon idealized elements of the firm's past that seek to express what members aspire to be rather than how they are perceived by others.

We found that the inconsistency between projected identity and reputation was sufficiently serious for the firm's partners because it impinged upon their ability to win or sustain business as a so-called strategy consulting firm, which was their strategic aim. However, we also found that the multiple identities within the organization facilitated mechanisms to remediate (but not resolve, in a functionalist manner) this disconnect between identity and reputation.

The first mechanism shifted the level of attention and therefore of reputation from the organization to the partner and team. Such teams are the core production unit of the consulting firm and can operate with sufficient autonomy and stability, to be able to build strong identities particularly in interacting with clients (Gardner et al. 2013; Smets et al. 2012). Indeed, our findings of how the local partner teams focused on their particular competences and relationships to build a niche reputation resonates with Whittle's (2006) finding of the 'stage' activities of consulting teams. 
The second mechanism of shifting identity from a commercial to a 'disinterested expert' relationship at the partner team level also changed the client relationship. Here the consultants emphasized identities as professionals but both they and the clients were also aware that there was an underlying commercial rationale, so professionalism was tinged with a 'soft' instrumentalism. Shifts like this into a professional/commercial identity extends other work that has found consultants may use expertise claims creatively (e.g. Alvesson and Roberts 2006) or flex their roles and identities (Whittle 2006) by showing how this can be deployed to build or adjust a reputation.

The third mechanism of emphasizing value (through team composition and extra effort) is not unique to this case and has been found elsewhere as a way to build benevolence among clients (e.g. Sturdy et al. 2013; Nikolova et al. 2014) but our argument is that it is facilitated by a strong identity with the client and reinforced by being embedded within the client organization. It was designed to demonstrate requisite reputational qualities, such as competence and 'can-do' and required substantial commitment and extra effort by the consulting teams. Here, the culture of the consulting organization and the strong career incentives appeared to reinforce this particular mechanism.

Collectively, we argue that these mechanisms, underpinned by multiple identities focused around the partner team and the client, build client trust, which creates the capacity to bridge the gap between its projected identity claims and reputation. Existing theory shows that a strong reputation creates trust by building confidence among external parties that the focal firm is competent, holds integrity, can build a strong emotional connection with the client and demonstrate benevolence (Armbrüster 2004; Coffee 2006; Nikolova et al., 2014). We build on this by showing how trust is enabled through identity work via close partner relationships with clients, reassuring the client of its competencies and benevolence through additional activities such as thought leadership, and providing extra evidence of their identity through over-delivering on project work. The combination of providing tangible evidence of expertise through for example thought leadership activities coupled with using their close relationships with clients to explain their identity leads to greater flex between identity claims and reputation.

\section{CONCLUSIONS}

This paper starts by recognizing that the identity claims of firms may be markedly different from their reputation. We refer to this as reputational dissonance and argue that this is problematic because it affects the ability of the focal firm to sustain the sort of external interactions (such as deal winning) that it seeks. We argue that there are a number of remedial actions that firms can adopt which are underpinned by different types of identities within the firm. Using these multiple forms of identity facilitates trust-building with clients. As a result, their core organizational identity is not compromised and reputational dissonance is managed, but not necessarily resolved. In summary, this paper contributes to the literature on identity and reputation by demonstrating that the relationship between these concepts is not always consistent and that the existence of multiple forms of identity provide a means to deal with the dissonance between them.

\section{REFERENCES AVAILABLE FROM THE AUTHORS}

